NBER WORKING PAPER SERIES

\title{
MEASURING THE EFFECTS OF WORKLOSS ON PRODUCTIVITY WITH TEAM PRODUCTION
}

\author{
Sean Nicholson \\ Mark V. Pauly \\ Daniel Polsky \\ Claire Sharda \\ Helena Szrek \\ Marc L. Berger \\ Working Paper 10632 \\ http://www.nber.org/papers/w10632
}

\author{
NATIONAL BUREAU OF ECONOMIC RESEARCH \\ 1050 Massachusetts Avenue \\ Cambridge, MA 02138 \\ July 2004
}

We would like to thank Merck \& Co., Inc. for providing funding for this research project. We received helpful comments from participants at the International Health Economics Association $4^{\text {th }}$ World Congress meeting. The views expressed herein are those of the author(s) and not necessarily those of the National Bureau of Economic Research.

(C)2004 by Sean Nicholson, Marc V. Pauly, Daniel Polsky, Claire Sharda, Helena Szrek, and Marc L. Berger. All rights reserved. Short sections of text, not to exceed two paragraphs, may be quoted without explicit permission provided that full credit, including (C) notice, is given to the source. 
Measuring the Effects of Workloss on Productivity With Team Production

Sean Nicholson, Marc V. Pauly, Daniel Polsky, Claire Sharda, Helena Szrek, and Marc L.

Berger

NBER Working Paper No. 10632

July 2004

JEL No. I10, J30

\section{$\underline{\text { ABSTRACT }}$}

Using data from a survey of 800 managers in 12 industries, we find empirical support for the hypothesis that the cost associated with missed work varies across jobs according to the ease with which a manager can find a perfect replacement for the absent worker, the extent to which the worker functions as part of a team, and the time sensitivity of the worker's output. We then estimate wage "multipliers" for 35 different jobs, where the multiplier is defined as the cost to the firm of an absence as a proportion (often greater than one) of the absent worker's daily wage. The median multiplier is 1.28 , which supports the view that the cost to the firm of missed work is often greater than the wage.

\begin{tabular}{|c|c|c|}
\hline Sean Nicholson & Mark V. Pauly & Daniel Polsky \\
\hline The Wharton School & The Wharton School & Department of Medicine \\
\hline University of Pennsylvania & University of Pennsylvania & University of Pennsylvania \\
\hline 3641 Locust Walk & 3641 Locust Walk & Blockley Hall, $12^{\text {th }}$ Floor \\
\hline $\begin{array}{l}\text { Philadelphia, PA } 19104 \\
\text { and NBER }\end{array}$ & $\begin{array}{l}\text { Philadelphia, PA } 19104 \\
\text { and NBER }\end{array}$ & $\begin{array}{l}\text { Philadelphia, PA } 19104 \\
\text { polsky@mail.med.upenn.ed }\end{array}$ \\
\hline cho & $t 50$ & \\
\hline Claire Sharda & Helena Szrek & Marc L. Berger \\
\hline USHH Outcomes Research & The Wharton School & USHH Outcomes Research \\
\hline \& Management & University of Pennsylvania & \& Management \\
\hline Merck \& Co., Inc. & 3641 Locust Walk & Merck \& Co., Inc. \\
\hline 770 Sumneytown Pike & Philadelphia, PA 19104 & 770 Sumneytown Pike \\
\hline WP39-166 & szrek@wharton.upenn.edu & WP39-166 \\
\hline $\begin{array}{l}\text { West Point, PA } 19486 \\
\text { claire_sharda@merck.com }\end{array}$ & & $\begin{array}{l}\text { West Point, PA } 19486 \\
\text { marc_berger@merck.com }\end{array}$ \\
\hline
\end{tabular}




\section{Introduction}

Missing work due to an illness reduces a worker's contribution to a firm's output and profits. However, since activities to prevent or limit workloss are almost certain to be costly, convincing businesses to engage in these activities requires getting some idea of how large the reduction in output is, and how it differs across workers in different jobs. Constructing a valid and accurate estimate of the value of lost output due to illnesses will also help to assess the value of improvements in the quality of medical care that enhance functional status.

Our earlier work (Pauly et al., 2002) posed a theoretical challenge to conventional methods of measuring the value of workloss by the daily wage - the "compensation cost" method of measuring the value of lost productivity (e.g., Stewart et al., 2003a and 2003b). Such measures may be appropriate for certain jobs where workers perform discrete and measurable tasks undertaking what is essentially piecework. Our concern is that many jobs in the modern economy, especially those in knowledge industries, are not performed in isolation, but instead require workers to function as members of a team, where both the timing and the performance of one worker affects the others. We therefore hypothesized, and developed a model to demonstrate, that when certain job and output characteristics were present, the consequences to employers of missed work (in firms that pay sick leave benefits) could be substantially greater than the worker's wage.

This paper reports on research intended to extend this model and test it empirically. Specifically, we test the hypothesis that the cost or productivity loss associated with missed work varies across types of jobs with the specific characteristics our theory identified, and that the cost can be much higher than the wage in jobs with those characteristics. Not only do we test this hypothesis, we also estimate a "multiplier" for an illustrative set of jobs of different types, where the multiplier is defined as the cost of an absence as a proportion (often greater than one) of the absent worker's daily wage. Managers can use these estimates to determine the cost of absence 
by multiplying the worker's wage by the appropriate multiplier for that job, or for a job with the same combination of job characteristics.

\section{Job Characteristics and Productivity Loss}

Our earlier work defined three necessary conditions for the consequences of workloss to be greater than the wage (i.e., for the multiplier to be greater than one). First, the employer must be unable to find a replacement worker who is a perfect substitute (in terms of productivity) for the absent worker at the same compensation cost as the absent worker. If managers can find a perfect substitute at the same wage, the substitution would occur and the cost of an absence would just be the wage of the absent worker. ${ }^{1}$

The second necessary condition for a multiplier to exceed unity is that production must occur in a "team" setting. Here we interpret a "team" as a production process in which the input of any one member affects the productivity of other members, in a complementary fashion, so that output cannot be attributed to any single worker. Consider a situation where a worker in a group consulting project becomes ill and no substitute with that person's specialized knowledge can be found. If the project cannot be completed on time and some or all revenue is lost, the cost of that worker's absence can be substantially greater than his/her wage for this time period.

The third necessary condition is that there must be "time sensitivity" to firm-level demand, in the sense that price or revenue will fall if output is lost or postponed. An absence by a key member of a team could result in lost sales whose value could greatly exceed not only the worker's wage, but even those of all team members. The lost revenue due to a cancelled airline flight, for example, could be many times larger than the sum of the wages of the crew.

We therefore want to determine whether jobs vary in an identifiable away across the three characteristics: "teaminess," ease of finding a substitute, and time sensitivity of customers. If it were possible to measure output and therefore productivity directly, one could estimate

\footnotetext{
${ }^{1}$ If a perfect substitute had a lower wage, the firm should fire the worker and hire the substitute.
} 
empirically the impact of absences in jobs with different amounts of these characteristics. However, it is virtually an inherent characteristic of the types of jobs and outputs we wish to examine that there is no easy way to measure even a team's total output, and that it is virtually impossible to attribute total output to different workers or other inputs. That is, when one can accurately measure a worker's total output, it is almost always the case that the person works in isolation (e.g., at a call center). While one can in principle measure the total output of a team, there is no method for performing the Solomonic task of dividing that output among the team members. Even if it were conceptually possible, performing this task would require detailed microdata, which most firms do not collect as part of their management process. We therefore view the multiplier as a characteristic of work that experienced managers can evaluate, but which is difficult for an external observer to measure objectively and consistently across a wide variety of jobs and settings, and therefore difficult to "prove" to others. It is often this absence of objective data that makes it difficult to make a business case for actions that avoid or reduce absences.

An analogy that may be helpful is the problem of measuring the "quality of life." In health outcomes research, the quality of life is almost never measured directly but is thought to be an important characteristic. Our goal in the research reported here, therefore, is to ask managers about the "quality of absences" that are associated with different jobs, to use their responses to estimate a multiplier.

\section{Conceptual Model and Empirical Methods}

The cost of an absence is the dollar value of the firm's lost output that results from the absence. Until recently, most economists assumed that the cost of an absence was a worker's wage. Pauly et al. (2002) argue that if competitive labor markets are in equilibrium, a worker's wage is the lower-bound estimate of the cost of an absence. If, for example, firms can predict absences perfectly and hire enough workers to cover for the absent workers, absences should 
have no impact on the firm's output. When negotiating a worker's wages, however, the firm should take into consideration how much he is expected to produce only on days when he is present. Therefore, a worker's annual salary should be reduced (relative to a situation where the worker is never absent) by the value of the worker's daily output multiplied by the number of days he is expected to be absent. Since a worker's wage is the best estimate of his marginal revenue product, the wage per day worked (or suitably adjusted, the wage per day paid) is the lower-bound for the cost of an absence.

Our objective is to define a multiplier of this wage (by job type) that reflects the true cost of an absence in that job. The multipliers will vary across jobs based on the presence and importance of the three characteristics: the likelihood that a manager can find a perfect substitute for the absent work, the extent to which the worker functions in a team, and the extent to which the worker's output or his team's output is time sensitive. The loss in output resulting from a single-day absence, L, is:

(1) $\mathrm{L}=\mathrm{mw}$,

where $\mathrm{m}$ is the multiplier we seek to estimate and $\mathrm{w}$ is a worker's daily wage. The multiplier in turn is defined as:

(2) $\mathrm{m}=(\mathrm{c}+\mathrm{a}) / \mathrm{a}$, where a is the percentage of scheduled days a worker is absent, and $\mathrm{c}$ is the annual cost of a worker's absences in excess of their wage, measured as a percentage of the worker's annual pay. The multiplier could be greater than one if, for example, if an absence causes the worker's teammates to be idle, if the firm pays overtime for another worker to replace the absent worker, or if the firm loses sales due to the absence.

If an equally-productive substitute worker could be hired at wage w to replace an absent worker, c would be zero and the multiplier would be one. However, suppose a worker is absent four percent of the days and his manager estimates that the incremental annual cost (above the wage the worker is paid) is an additional two percent of the worker's annual pay. Then the 
multiplier would be 1.5 (or $((0.02+0.04) / 0.04)$ ). If the worker's daily wage were $\$ 100$, the cost of a day missed would be $\$ 150$.

To derive the multiplier, a valuation of the cost to the firm of absences by a particular type of worker is needed. To estimate this value, we borrow from the methodology used to value quality of life where there are two common approaches: the direct measurement of values (Froberg and Kane, 1989) and measurement based on a classification system (Drummond et al., 1997; The EuroQol Group, 1990; and Torrance et al., 1996). We focus on establishing a jobclassification system because it may be easier for those directly involved in the management of the workers in a particular firm to classify a job than to directly estimate the cost to the firm of absences by a particular type of worker.

We do this by asking managers to assess how a worker's absence affects the output of his or her department using a 1 to 5 categorical scale, and also to assess the presence of the three characteristics of the job using a 5-point scale for each characteristic. We hypothesize that the multiplier $\mathrm{m}$ is a latent variable whose value is a function of the three key job characteristics: team production (TP), time sensitivity (TS), and availability of substitutes (AS). We test this hypothesis and estimate how much each characteristic contributes to the value of work lost due to absences. Using an ordered probit, we regress managers' categorical responses to questions about the extent to which absences by a particular type of worker affect the department's output on a set of indicator variables that characterize managers' assessments of the workers' job characteristics:

(3) $\mathrm{L}^{*}=\$_{1} \mathbf{T P}+\$ \$_{2} \mathbf{T S}+\$ \$_{3} \mathrm{AS}+$,

$\mathrm{L}^{*}$ is a latent, continuous variable. What we actually observe is that $\mathrm{L}=1$ (i.e., a manager reports that an absence has no impact on his department's output) if $L^{*} \#:{ }_{1} ; \mathrm{L}=2$ if : $<\mathrm{L}^{*} \#:{ }_{2}$, and so forth. The cutoff values $\left(:_{1},:_{2}\right.$, and $\left.:{ }_{3}\right)$ are estimated along with the coefficients, $\$$. 
However, we go farther than testing the hypothesis that these characteristics matter. We also use the coefficients from this regression and information on the values of TP, TS, and AS for a variety of jobs to construct an index of the incremental cost of absences by job. Conceptually this index measures the incremental cost of an absence for the given job relative to the cost of absences for other jobs. To convert this index to a measure of the actual incremental cost, $\mathrm{c}$, we need to scale the index. We do so by using the quantitative value from two questions directed at ascertaining a manager's estimate of the monetary value to the firm of avoiding absences for this job. We chose this approach because we expected (and observed) that the quantitative question had more noise in its responses; the categorical responses used to construct the index had greater reliability.

\section{Data}

We identified 57 jobs in 12 industries that involve a broad range of important job characteristics (e.g., team versus individual production; service versus manufacturing; easy versus difficult to substitute for an absent worker). The industries are described at the bottom of Table 2. We contracted with the survey firm Harris Interactive to create a random sample of establishments within these industries stratified by the number of employees in the establishment $(1-99 ; 100-499 ; 500$ or more) and whether or not the establishment is the firm's headquarter or a branch location. Harris Interactive contacted managers at these firms who supervised one of the 57 targeted job types and had sufficient experience to be able to describe what happens when a worker is absent.

Ninety-one percent of the eligible managers completed the phone survey, which took about 15 minutes on average. Thirty-nine of the 804 managers that were interviewed provided information on two jobs, so the data set consists of 843 observations on a particular job. Managers were asked to provide information on the structure of their department and firm (e.g., number of employees of the relevant job type, average wage, and absence rate). They were also 
asked about the extent to which the three characteristics (teamwork, ease of substitution, and time sensitivity) were embodied in a given job. The questions about the three key job characteristics are presented in Table 1. Managers were asked to indicate on a 1 to 5 scale how easily they could find a replacement of equal quality or productivity if a worker was absent unexpectedly for three days. A ' 1 ' indicates it is easy to find such a replacement and a ' 5 ' that it is impossible. Using the same scale, mangers reported the extent to which a specific type of worker functions as a part of a team and the degree of time sensitivity of their output.

Managers' responses, which are reported in Table 2, indicate that the jobs vary substantially along these three dimensions. For example, across all the jobs we studied, 22 percent of the managers indicated it was easy to replace an absent worker with an equally productive substitute ( $\mathrm{a}^{\prime}{ }^{\prime}$ '), nine percent indicated to was impossible to do so (a ' 5 '), while 22 percent, 27 percent, and 20 percent responded with a '2', '3', or '4', respectively. ${ }^{2}$

We designed two questions to elicit from managers categorical answers about the consequences of absences. The first two questions, detailed at the bottom of Table 1, ask managers to record separately the impact of an unexpected 3-day and 2-week absence on the work of the department using a 1 to 5 scale. A ' 1 ' indicates that the absence has no effect and a ' 5 ' indicates the absence causes the department to shut down. Since these are categorical variables, they can be used to create a relative measure of workloss costs (an index), but cannot directly provide a dollar-based estimate of the value of work lost due to absences. We present managers' responses to these two questions at the bottom of Table 2. Twenty-nine percent of the managers believed a 3-day absence would have no effect on the department's output and only 0.9 percent indicated the absence would essentially shut down the department. As expected, a longer absence is more likely to have a substantial impact on output. Since few managers responded

\footnotetext{
${ }^{2}$ There is also considerable variation in the other two job characteristics. Ten percent of managers reported that work could be postponed easily if a worker was absent, whereas 27 percent indicated there would be severe consequences associated with postponing work. Thirteen percent of the workers function separately from other members of the department, while 15 percent are such crucial members of a team that the team would produce no output if the person were absent unexpectedly.
} 
with a " 5 " to either question, we combine the values of four and five when running the ordered probit regressions.

Managers were also asked two quantitative questions to elicit estimates of $\mathrm{c}$ in equation (2). One asked them to estimate how much absences by a particular type of worker affect the firm's costs over the entire year (not including the worker's wages) due to factors such as overtime and lost sales. Managers reported the cost as a percentage of a worker's annual pay, so this measure can be used to scale the latent measure based on either the 3-day or 2-week questions. Managers were also asked to indicate how much they would be willing to pay an imaginary hiring agency that would send a perfect substitute whenever a worker was absent. As before, managers reported this willingness to pay as a percentage of a worker's annual pay, so this variable is denominated in dollars just as is the overall cost of absence variable. According to the surveyed managers, the mean cost of absences as a percentage of a worker's annual pay is 7.4 percent, and the mean willingness to pay a hiring agency for a perfect substitute is 8.2 percent of a worker's annual pay (see Table 2). There is, however, considerable variation in managers' assessment of the quantitative cost of absences, as is evident from the distributions plotted in Figure 1 and Figure 2. Although more than 10 percent of the managers reported that the overall annual cost of a worker's absence, not including his wages, is zero, a substantial number gave considerably higher cost estimates. ${ }^{3}$

\section{Results}

Sample statistics are presented in Table 2. The managers' responses to the categorical questions regarding the impact of a 3-day and a 2-week absence (ranging from 1 to 5) exhibit some variability. For the 3-day absence question, 95 percent of the responses range from 1 to 3 , with 2 being the modal response. For the 2 -week absence question, 79 percent of the responses range from 1 to 3, with 3 being the modal response. The 3-day and 2-week questions ask 
managers to assess a similar concept -- the impact of an absence. The correlation between the two categorical "impact of absence" questions is large, positive (0.63), and highly significant. The fact that managers responded consistently to these two questions and believe that a 2 -week absence has a larger impact than a 3-day absence, as expected, provides evidence that managers understood these questions. The correlation between managers' responses to the two quantitative questions (the overall annual cost of absences and the willingness to pay for a perfect substitute, measured as a percentage of a worker's annual pay), on the other hand, is much lower (0.14). Furthermore, the standard deviations of the categorical variables are less than one-half of their respective means (not shown in Table 2), while the standard deviations for the two quantitative, continuous variables are larger than their means (Table 2). Since there appears to be more measurement error with the quantitative measures, we use the categorical variables to construct the cost-of-absences index and scale the index using the quantitative variables.

We begin by giving some descriptive results regarding managers' perceptions of what happens when a worker has an unexpected absence due to illness that causes him to miss three days of work. For a large percentage of jobs (83 percent), other members of a worker's department both perform their usual responsibilities and pick-up the absent worker's responsibilities, whereas in 26 percent of the jobs another department member fills in but does not complete his or her usual responsibilities. ${ }^{4}$ Twenty-three percent of absent workers make up their work when they return, and 10 percent make up their work in subsequent evenings or weekends.

Among managers that obtain substitute workers for absent workers, in 53 percent of these jobs the substitutes are perceived to be equally effective as existing workers. Substitutes are more effective than existing workers in only three percent of jobs, less effective in 35 percent, and much less effective in nine percent. In over one-half of the jobs, therefore, a manager either does not replace an absent worker or replaces the worker with a less productive worker.

\footnotetext{
${ }^{3}$ We top-coded the overall cost of an absence and managers' willingness to pay for a perfect substitute at 30 percent of a worker's annual wage.
} 
Managers were also asked to indicate the most serious consequence of an unexpected 3day absence. One-third of the managers reported there would be no serious consequences associated such an absence, and 13 percent indicated that low-priority tasks in the department would not be completed. At the other extreme, in seven percent of the jobs an absence would result in lost sales or would cause customers to move to competitor firms because the firm was unable to provide a product or service. Six percent of the managers reported that the absence would cause external deadlines to be missed, and 10 percent reported that internal deadlines would be missed or members of a team would not be able to move forward with their work.

We test our hypothesis that the managers' estimates of the consequences of absences are positively associated with the three job characteristics thought to be important: the extent to which a worker functions as part of a team, the ease with which a manager can substitute for an absent worker, and the time sensitivity of a worker's output. In Table 3 we present results of an ordered probit regression where the dependent variable is a manager's estimate of the impact of an unexpected 2-week absence on the department's output, and the independent variables are 12 indicator variables that characterize the three job characteristics. ${ }^{5}$ Team_2 is an indicator variable that takes on the value one when a manager perceives the job has a team work value of 2 on a scale from 1 to 5, Team_ 3 is an indicator variable that takes on the value one when a manager perceives the job has a team work value of 3 , and so forth. We apply this coding to all three of the job characteristics. (See Table 1 for a description of the three job characteristics and the scaling system.) The omitted categories are the categories that we hypothesize would have the smallest impact on the cost of absence. We estimate ordered probit models because the dependent variable is categorical (measured on a 1 to 4 scale, where 1 indicates no effect and 4 indicates the department is shut down because of the absence).

\footnotetext{
${ }^{4}$ The managers' responses are not mutually exclusive; they were asked to indicate all situations that occur when a worker is absent for three days.

${ }^{5}$ Coefficients using the impact of a 3-day absent are qualitatively similar, and regression results using the impact of a 3-day absence as a dependent variable are available from the authors by request. In Table 4 we compare multipliers using a 3-day versus a 2-week impact of absence dependent variable.
} 
Based on our theory, all of the coefficients should be positive and the coefficient on Team_3 should be larger than that on Team_2, the coefficient on Team_4 should be larger than that on Team_3, and so forth. Indeed, the coefficients on each of the 12 indicator variables are positive and significant; the hypothesized job characteristics are related to the impact of an absence. Moreover, the coefficients increase in the hypothesized fashion; managers believe that absences have a bigger impact when the job involves a relatively large amount of teamwork, it is difficult to postpone work, and it is difficult to substitute for an absent worker. The exception, however, is that the coefficients on jobs with the greatest amount of a particular characteristic (Team_5, Time Sensitivity_5, and Substitution_5) are smaller than the coefficients for jobs with slightly less of that characteristic. ${ }^{6}$ Overall, the regression results also confirm that managers are able to comprehend and respond to the question regarding the impact of an absence. ${ }^{7}$ The standard errors are relatively low, and the overall pattern of coefficients makes sense.

We also estimated a more general ordered probit regression that allows for interactions among the effects of the three job characteristics. In order to simplify the empirical specification, we grouped managers' responses of one and two into a "low" category, three into a "medium" category, and values of four and five into a "high" category, separately for each of the three job characteristics. The terms "low", "medium", and "high" indicate the extent to which the manager believes the worker functions as part of a team, the time sensitivity of the output, and the ease of substituting for the worker. We then included 26 separate indicator variables that represent all of the different combinations of managers' assessments of the workers' job characteristics. The estimates are interpreted as the effect of an absence in the given job relative to a job where the

\footnotetext{
${ }^{6}$ In a series of one-tailed tests, we find that the coefficients on Team_3 and Team_4 are significantly larger than the coefficient on Team_2, and the coefficient on Team_4 is larger than the coefficient on Team_3. The coefficient on Time Sensitivity_4 is significantly larger than the coefficient on Time Sensitivity_2, but none of the other ordered relationships hold for that job characteristic. Finally, the coefficients on Substitution_3, Substitution_4, and Substitution_5 are all significantly larger than the coefficient on Substitution_2.

${ }^{7}$ The coefficients on the job characteristic variables change very little when we include industry indicator variables, and the industry indicators are not jointly significant in either the 2-week or 3-day regression. In these specifications the coefficients on the job characteristics are identified by variation across firms within
} 
worker functions independently, the work can be postponed easily, and it is easy to find a perfect substitute if the worker is absent. Indeed, almost all of the coefficients (not shown) on the job characteristics categories are positive and significant at the 10-percent level (22 out of 26 coefficients), and none of the coefficients is negative and significant. The coefficients on jobs where all three characteristics were perceived by managers to be medium or high were generally much larger than for jobs where at least one of the characteristics was considered to be low or absent altogether. ${ }^{8}$

We derive job-specific multipliers using a multiple-step process. First, we use the regression coefficients from Table 3 and the job characteristics to derive a predicted value of the latent, continuous variable underlying the categorical dependent variable ( $\mathrm{L}^{*}$ from equation 3 ) for each of the 810 manager responses. Second, we calculate the mean value of the predicted latent variable for each of the 57 job types included in our survey. We then link the mean predicted value of the latent variable for each job type to the quantitative measure of the cost of absences (the manager's assessment of the overall annual cost of absences) in order to scale the index, as shown in Figure 3. For example, if the mean predicted latent value for registered nurses was 1.46 , this would place it at the $30^{\text {th }}$ percentile of that distribution (bottom row of Figure 3 ). In this case we would link this value to the $30^{\text {th }}$ percentile of the distribution of managers' estimates of the overall cost of absences, which is $1.0 \%$ of a worker's annual pay. ${ }^{9}$ Finally, we substitute the quantitative estimate of the cost of absences into equation (2) along with the mean absence rate of each job type to derive the multiplier. Therefore, the 2-week absence categorical variable allows us to create an index of the relative impact of absences across different jobs, and the quantitative variables scale this index into a dollar-denominated value.

\footnotetext{
a particular industry. The stability of coefficients even when we include industry indicators implies that the job characteristic variables are capturing most of the important information about workloss costs.

${ }^{8}$ Results are available from the authors by request.

${ }^{9}$ In order to be consistent, we link the latent variable by job type to the distribution of responses for the 406 managers who provided estimates for both the overall cost of absences and the willingness to pay for a perfect substitute.
} 
In Table 4 we present multipliers in descending order for the 35 jobs with at least five observations in the survey. The multipliers range considerably from 1.00 to 11.4 , although only one is above $2.00 .^{10}$ When a cook at a fast food restaurant, a waiter, or a server at a fast food restaurant is absent, we estimate that the cost of the absence is very close to the daily wage. When an aerospace engineer is absent, by contrast, we estimate that the cost is 70 percent greater than his or her daily wage.

The equal-weighted mean multiplier for the 35 jobs is 1.61 and the median multiplier is 1.28. ${ }^{11}$ These results imply that, according to our methodology, the cost of an absence for many jobs is considerably larger than the daily wage of the absent worker. In general the relative ranking of the multipliers seems intuitive. Construction and aerospace engineers, with large estimated multipliers, are well educated, have relatively high salaries, work as part of a team, and often operate under tight deadlines that may have associated revenue penalties. Likewise, paralegals, medical assistants, and legal secretaries work closely with and affect the productivity of physicians and lawyers, who can generate substantial additional revenue when they produce additional services. These workers also operate under tight deadlines and their firms may lose billings and/or future business when their work is not completed promptly.

The multipliers are significantly but by no means perfectly correlated $(0.38)$ with the mean wage of the job type. Thus, our multiplier methodology is not merely a function of a worker's wage. A relatively low-paid car salesperson has a large multiplier, presumably because the marginal profit of a single sale is large and a dealership may lose sales to its competitors when a salesperson is absent. A restaurant cook likewise has a large multiplier because her firm may lose revenue when she is absent. Many of the low multipliers are in jobs with low wages where it is probably relatively easy to substitute for an absent worker, such as fast food cooks, waiters, and

\footnotetext{
${ }^{10}$ The multiplier for a construction engineer is extremely large, in part, because there were relatively few responses from people managing construction engineers (eight in our survey, as can be seen in column 3 of Table 3), the absence rate for this job is particularly low, and the cost of absence distribution is skewed to the right. The correlation between the two categorical "impact of absence" questions is 0.63 and is highly significant, which suggests that managers responded consistently to these two questions.

${ }^{11}$ The mean multiplier is 1.33 if construction engineers are excluded.
} 
maids. Some jobs with relatively high wages, like a construction worker, have a low multiplier because it is relatively easy to find a replacement worker and they tend to work individually rather than in a large team.

We examined how sensitive the multipliers are to alternative specifications. In the fourth column of Table 4 we present multipliers based on an ordered probit regression where the dependent variable is a manager's assessment of the impact of a 3-day absence on the department's work, rather than a 2-week absence as we used in the baseline specification. Few of the multipliers change substantially. The 3-day and 2-week multipliers are highly correlated (0.94), and the relative rankings of the jobs are similar regardless of which dependent variable we use. Likewise, the multipliers derived from the more complex but less restrictive specification that allows for interactions among the effects of the three job characteristics are similar to those presented in Table 3 (correlation of 0.63 ).

We also calculate multipliers using the regression coefficients from Table 3 but scaling the latent variable using managers' assessments of their willingness to pay a hiring agency for a perfect substitute rather than managers' perceptions of the overall annual cost of absences. ${ }^{12}$ The correlation between these two sets of multipliers is 0.99 , which confirms that the relative rankings of the jobs do not change much regardless of which of the two quantitative variables we use as a scale. The multipliers in the latter specification are less sensitive than in our baseline model; there is less variation across jobs in the magnitude of the multipliers.

Since we were concerned that the multipliers may be sensitive to how we scale them, we also calculated multipliers if the distribution of the cost of absence variable were "shifted" down by 20 percentile points. ${ }^{13}$ The mean multiplier is reduced from 1.61 to 1.17 , and the effect is especially pronounced for jobs that had the highest multipliers. However, 54 percent of the jobs

\footnotetext{
${ }^{12}$ Results of the multipliers using the willingness to pay scaling variable are available from the authors by request.

${ }^{13}$ For the latter analysis, if a job has a predicted latent variable at the $30^{\text {th }}$ percentile of the distribution based on the manager's estimated impact of an absence on the department's output, for example, we link this to the $10^{\text {th }}$ percentile of the overall cost of absence distribution.
} 
still had a multiplier above 1.0. ${ }^{14}$ The multipliers in Table 4 should be viewed as approximations, or estimates, of the true impact of an absence to an employer. The fact that the ordering of the multipliers is robust to the use of alternative dependent variables, scaling variables, and regression specifications, and the fact that the majority of the multipliers exceed one even when we use a conservative scaling methodology, provides evidence that the underlying empirical methodology is valid.

\section{Conclusion}

Analysis of survey data provides strong empirical support for the hypothesis that workloss from some jobs is thought by managers to be substantially more consequential to the firm than that from others, and that the consequences vary with the three job characteristics identified in our theory. That is, managers think that workers who are hard to replace and who work in teams producing time sensitive output cause greater productivity loss, other things equal. Determining the level of the three hypothesized characteristics in different jobs may therefore help firms in planning more targeted efforts to reduce the adverse consequences of workloss.

But this research goes beyond demonstrating the hypothesis that workloss matters in different ways for different jobs. It supports the view that the cost to the firm of missed work can be greater than the wage. Even more importantly, it develops and illustrates a method for developing empirical estimates of the (greater-than-one) wage multipliers implied by the theory. It does this by constructing an index of workloss and then converting that index into wage multipliers. In the context of national survey, the pattern of multipliers generated from the use of this method has high face validity, and is highly robust. The concept of an absenteeism multiplier may be highly useful.

There are limitations to the tests of this method that we have undertaken so far. For example, managers may have misperceptions of the consequences of workloss, so that their

\footnotetext{
${ }^{14}$ Results are available from the authors by request.
} 
responses cannot support the development of a valid measure. One would ideally prefer a "gold standard" measure of actual lost productivity, but the difficulty of obtaining such a method is the rationale for developing the approach described here.

A next step would be to apply this method to analysis of the consequences for productivity when sick workers actually come to work but have "impaired presenteeism" due to illness (such as depression, migraine headache, etc.). We would hypothesize that the adverse consequences of lower presenteeism would also be greater in jobs with the three characteristics we have identified. If this hypothesis is correct, it may be possible to develop similar methods to generate a presenteeism multiplier as well. 


\section{References}

Drummond, M.F., B. O’Brien, G.L. Stoddard, G.W. Torrance. 1997. "Methods for the Economic Evaluation of Health Care Programmes." Oxford University Press.

The EuroQol Group. EuroQol: A new facility for the measurement of helath-related quality of life. Health Policy 1990;16:199.

Pauly, Mark V., Sean Nicholson, Judy Xu, Dan Polsky, Patricia Danzon, James F. Murray, and Marc L. Berger, "A New General Model of the Impact of Absenteeism on Employers and Employees," Health Economics 2002; 11(3): 221-231.

Stewart, Walter F., Judith A. Ricci, Elsbeth Chee, Steven R. Hahn, and David Morganstein, 2003a, "Cost of Lost Productive Work Time Among US Workers With Depression," Journal of the American Medical Association 289(23): 3135-3144.

Stewart, Walter F., Judith A. Ricci, Elsbeth Chee, David Morganstein, and Richard Lipton, 2003b, "Lost Productive Time and Cost Due to Common Pain Conditions in the US Workforce," Journal of the American Medical Association 290(18): 2443-2454.

Torrance GW, Feeny DH, Ferloing WJ, et al., "Multiattribute Utility Function for a Comprehensive Health Status Classification System: Health Utilities Index Mark 2." Medical Care 1998; 34(7): 702-722. 
Table 1: Definition of Key Variables

\section{Characteristics of the jobs}

Ease of substitution: "How easy is it to replace this worker (either with an outside temp or a transferred co-worker) during a 3-day absence? Please use a scale where 1 is 'easy to replace with a worker of similar quality or productivity' and 5 is 'impossible to replace'." Interviewer's prompt, if necessary: "A ' 1 ' means there is a pool of workers you can access whenever you want and these workers are just as productive as the absent workers; a ' 5 ' means there is nobody else you could possibly find in three days who could do as good a job as the absent worker."

Time sensitivity: "How time sensitive is this worker's output using a scale where 1 is 'work that can be postponed easily' and 5 is 'work that cannot be postponed without very severe consequences'?" Interviewer's prompt, if necessary: "For example, a ' 1 ' means that the worker can complete their work the following day and no sales are lost and no important deadlines are missed; a ' 5 ' refers to a situation where sales would be lost and/or important deadlines would be missed if a worker were absent."

Teamwork: "How much does this worker function as part of a team using a scale where 1 is "the worker functions entirely separately from other workers' and 5 is 'the worker is such a crucial member of the team that the team's output or activity is wiped out by his or her absence'?" Interviewer's prompt, if necessary: "For example, a ' 1 ' might be appropriate for a person who picks crops in a field all by himself; and a ' 5 ' might be appropriate for the conductor of an orchestra where the orchestra can't play without the conductor and the conductor is useless without the orchestra."

\section{Managers' estimates of absence costs}

Impact of a 3-day absence: "Consider a situation where a [type of worker] has an unexpected absence due to illness that causes them to miss 3 days of work.... What impact would a 3-day absence by a [type of worker] have on the output or work of your department or division? Please use a scale where 1 represents 'no effect at all' and 5 represents 'total shutdown'."

Impact of a 2-week absence: "Now consider a situation where a [type of worker] has an unexpected absence due to illness that causes them to miss 2 weeks of work. What impact would a 2-week absence by a [type of worker] have on the output or work of your department or division? Please use a scale where 1 represents 'no effect at all' and 5 is 'total shutdown'."

Overall cost of absences: "Earlier you said that these workers are paid about [daily wage based on manager's earlier responses] per day based on their salary or hourly wage. Overall, how much do you think an absence by this worker costs the firm, in terms of additional costs the firm incurs or sales lost due to the absence? Do not include any payments made to the absent worker. Please try to estimate, as best as you can, how much an absence of this type of worker costs the firm as a percentage of their daily wage."

Willingness to pay for perfect replacement: "Imagine there were a perfect hiring agency, and whenever a particular [type of worker] was sick, the agency would send you a perfect substitute who could perform the job exactly as well as the absent worker. Before the beginning of the year, you can pay a fixed amount to use this service whenever you need to. The payment would be the same if you never used the service or used it every day, and the service only pertains to a single worker. How much would you be willing to pay per year, in terms of a percentage of the worker's yearly wage, to be able to use this hiring agency?" 
Table 2: Sample Characteristics

Job Characteristics $(\mathrm{n}=810)$

\section{Ease of substitution}

$1 \quad$ Easy to replace worker

$21.8 \%$

22.2

27.4

20.1

4

5 Impossible to replace

8.5

$100.0 \%$

\section{Time Sensitivity}

$\begin{array}{lcc}1 & \text { Work can be postponed easily } & 9.8 \% \\ 2 & & 14.3 \\ 3 & & 27.9 \\ 4 & & 21.0 \\ 5 & \text { Penalty if work is postponed } & 27.0 \\ & & 100.0 \%\end{array}$

\section{Team Work}

1 Works alone $\quad 12.6 \%$

218.3

3234.2

420.1

$5 \quad$ Important member of a team $\quad \underline{14.8}$

$100.0 \%$

Manager's assessment of the impact of an absence $(n=810)$

$\underline{\text { 3-day absence }}$

$1 \quad$ No effect at all

2

3

4

5 Total shutdown of department
$28.8 \%$

38.8

27.2

4.3

$\underline{0.9}$

$100.0 \%$ $\underline{\text { 2-week absence }}$

15.4

28.8

34.9

18.2

2.7

$100.0 \%$

Continuous variables $(n=810)$

Overall cost of absences

(as a proportion of a worker's annual pay)

Willingness to pay for a perfect substitute 
Table 2 (continued): Sample Characteristics

Percentage of observations by industry $(n=810)$

Retail sales, department stores $\quad 8.4 \%$

Legal services $\quad 8.5$

Motor vehicle dealers (new and used) $\quad 8.2$

Hotels and motels $\quad 8.5$

Trucking and courier $\quad 8.2$

Hospitals 8.5

Motor vehicle and equipment manufacturing $\quad 8.3$

Air transportation, scheduled and courier $\quad 8.4$

Construction, non-residential 8.3

Aircraft parts and manufacturing $\quad 7.9$

Physicians' offices 8.5

Eating and drinking establishments $\quad \underline{8.3}$

$100.0 \%$ 
Table 3: Ordered Probit Regression Coefficients for the Impact of a 2-Week Absence

$\begin{array}{lcc}\text { Indicator Variable } & \text { Coefficient } & \begin{array}{c}\text { Standard } \\ \text { Error }\end{array} \\ \text { Team_2 } & & \\ \text { Team_3 } & 0.360^{* *} & 0.144 \\ \text { Team_4 } & 0.588^{* *} & 0.133 \\ \text { Team_5 } & 0.930^{* *} & 0.147 \\ \text { Time Sensitivity_2 } & 0.531^{* *} & 0.154 \\ \text { Time Sensitivity_3 } & 0.485^{* *} & 0.166 \\ \text { Time Sensitivity_4 } & 0.581^{* *} & 0.158 \\ \text { Time Sensitivity_5 } & 0.685^{* *} & 0.165 \\ \text { Substitution_2 } & 0.385^{* *} & 0.157 \\ \text { Substitution_3 } & 0.587^{* *} & 0.119 \\ \text { Substitution_4 } & 0.950^{* *} & 0.121 \\ \text { Substitution_5 } & 1.08^{* *} & 0.129 \\ & 1.03^{* *} & 0.162\end{array}$

Observations

810

Cut points: $\quad$ Cut $1 \quad 0.493$

$\begin{array}{ll}\text { Cut } 2 & 1.57 \\ & (0.167)\end{array}$

Cut $3 \quad 2.68$

$(0.175)$

Percentage of observations correctly predicted: $42 \%$

Notes: The independent variables measure the extent to which each of the three job characteristics (team work, time sensitivity, and ease of substitution) are present in a job. Managers indicated on a 1 to 5 scale the extent to which a characteristic is present. With team work, for example, a " 1 " means the worker functions independently and a " 5 " means the worker is a vital member of a team (see Table 1 for a more complete description). Team_2 is an indicator variable that takes on the value one when a manager perceives the job has a team work value of 2, and so forth. The omitted variables are jobs where the worker functions independently (Team_1 is equal to one), work can be easily postponed (Time Sensitivity_1 is equal to one), and it is easy to find a replacement of equal productivity (Substitution_1 is equal to one).

$* *=$ significant at the 5-percent level. 
Table 4: Estimated Multipliers by Type of Job

\section{Type of Job}

Construction engineer
Paralegal
Medical assistant, physician's office
Aerospace engineer
Legal secretary
Mechanical engineer
Motor vehicle salesperson
Carpenter, non-residential construction
Restaurant cook
Flight attendant
Mover, trucking and courier
Registered nurse, hospital
Inspector, auto manufacturer
Inspector, aircraft manufacturer
Welder, auto manufacturer
Surgical technician, hospital
General office, retail sales
Truck driver, trucking and courier
Team assembler, automobile
Cashier, retail sales
Registered nurse, hospital operating room
Receptionist, physician's office
Medical records clerk, physician's office
Registered nurse, physician's office
Licensed practical nurse, physician office
Desk clerk, hotels and motels
Salesperson, retail sales
Bartender
Licensed practical nurse, hospital
Maids, hotels and motels
Construction worker, non-residential
Food service manager, restaurant and bar
Fast food server, restaurant and bar
Waiter, restaurant and bar
Fast food cook, restaurant and bar

2-week cost of absence multiplier

\subsection{0}

1.93

1.85

1.70

1.68

1.57

1.57

1.51

1.48

1.43

1.41

1.40

1.39

1.34

1.33

1.30

1.30

1.28

1.26

1.26

1.25

1.24

1.23

1.21

1.19

1.19

1.17

1.14

1.13

1.10

1.09

1.09

1.05

1.02

1.00

Mean $\quad 1.61$

$\$ 51,635$
$\$ 33,370$
$\$ 19,293$
$\$ 61,844$
$\$ 37,236$
$\$ 38,595$
$\$ 23,564$
$\$ 37,975$
$\$ 19,760$
$\$ 35,027$
$\$ 22,464$
$\$ 38,949$
$\$ 26,780$
$\$ 33,857$
$\$ 30,144$
$\$ 33,280$
$\$ 15,149$
$\$ 24,695$
$\$ 28,695$
$\$ 15,463$
$\$ 42,733$
$\$ 17,611$
$\$ 22,211$
$\$ 47,246$
$\$ 35,360$
$\$ 17,021$
$\$ 15,340$
$\$ 9,372$
$\$ 35,136$
$\$ 16,675$
$\$ 37,630$
$\$ 16,614$
$\$ 13,347$
$\$ 11,837$
$\$ 14,505$

3-day

cost of absence multiplier
4.47

2.13

2.26

1.70

1.61

1.54

1.54

1.48

1.32

1.43

1.50

1.40

1.28

1.29

1.38

1.30

1.30

1.28

1.26

1.27

1.29

1.27

1.23

1.28

1.24

1.23

1.17

1.24

1.13

1.14

1.09

1.06

1.07

1.00

1.00

Correlation with 2-week cost of absence multiplier

1.00

0.38

1.44

0.94 
Figure 1

Distribution of Managers' Assessments of the Overall Cost of Absences (as a \% of a worker's annual pay)

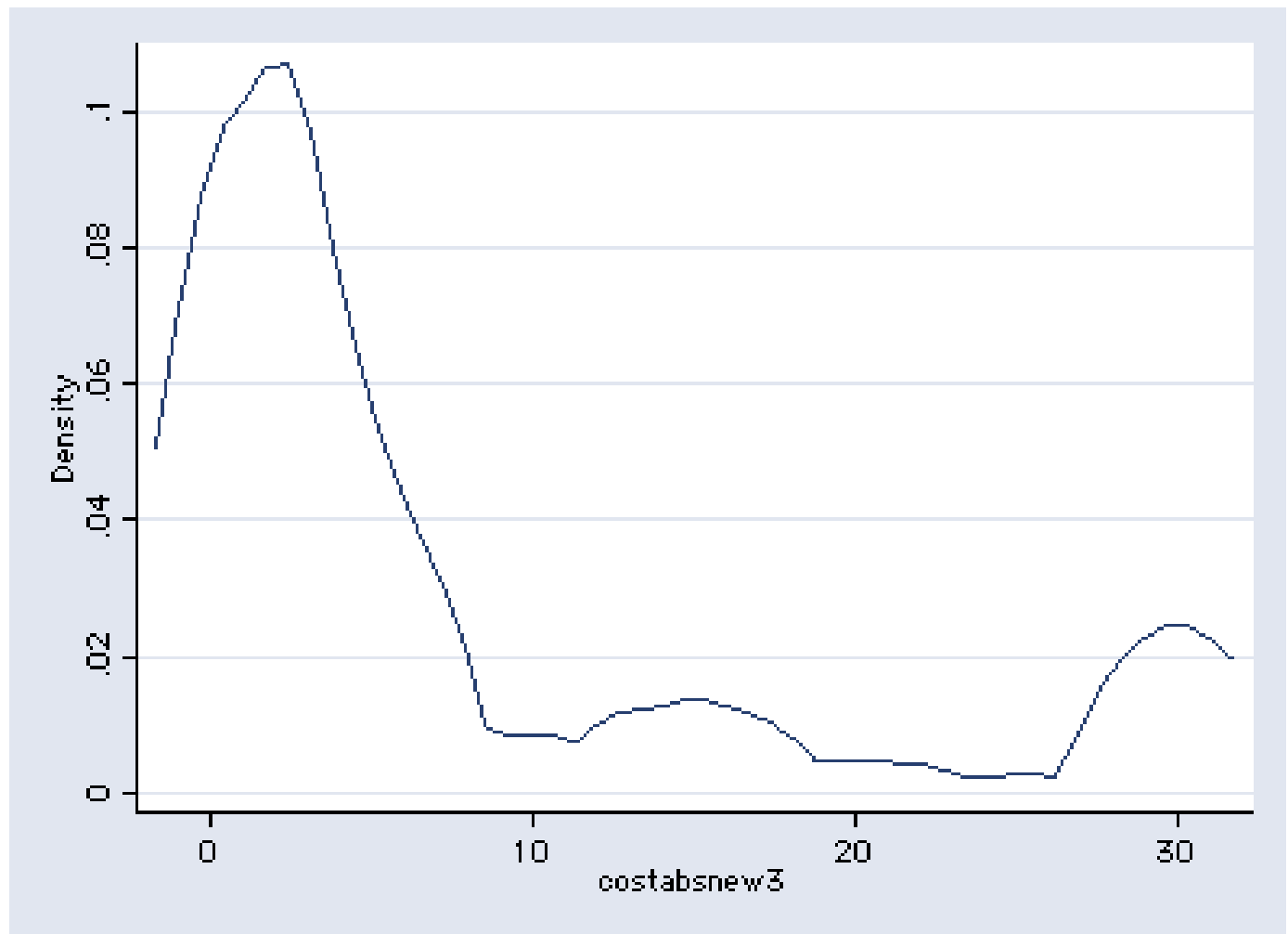


Figure 2

Distribution of Managers' Willingness to Pay for a Perfect Substitute (as a \% of a worker's annual pay)

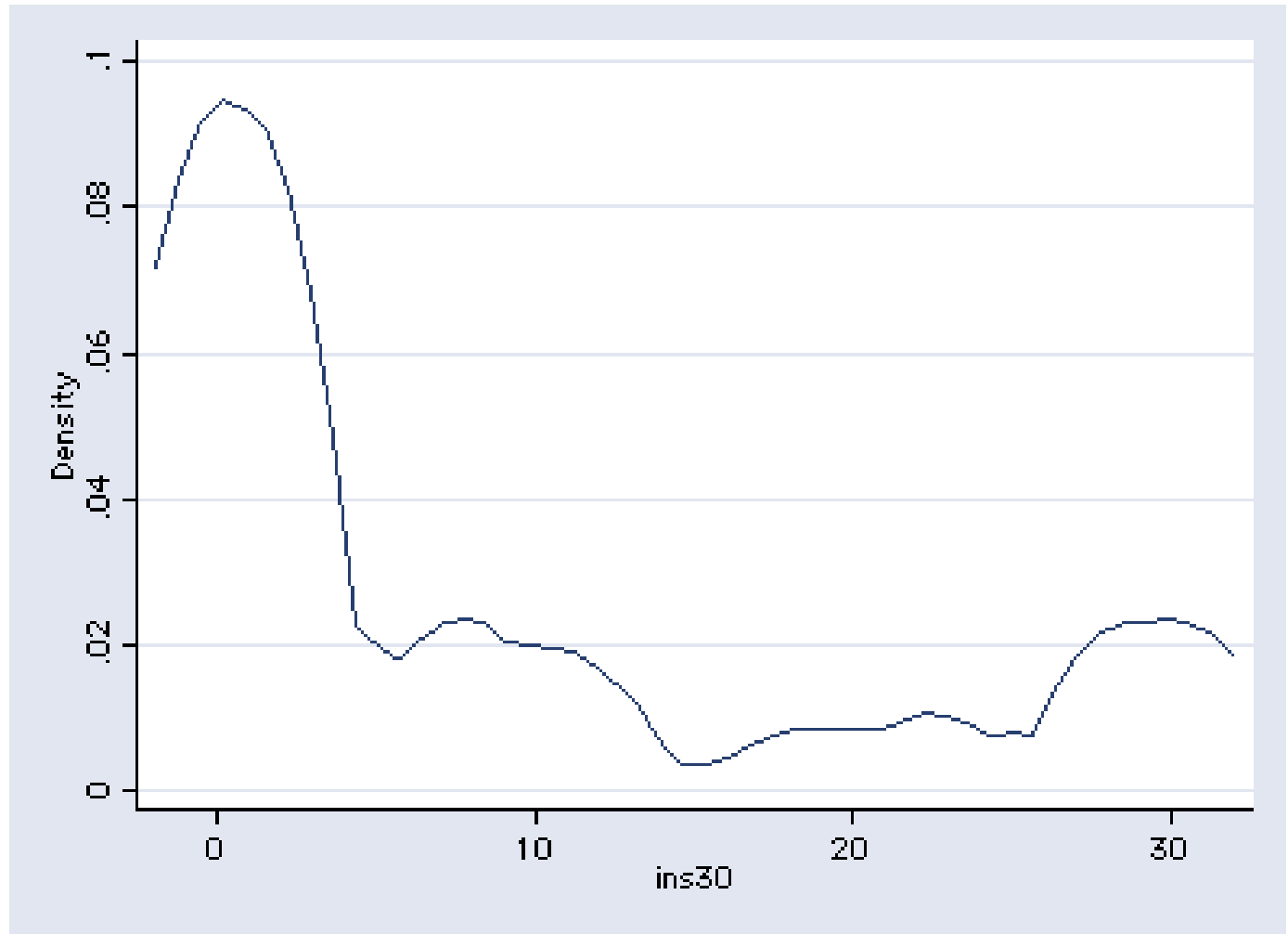


Corresponding

percentiles of

the overall cost

Figure 3

of absence

distribution (as a

$\%$ of worker's pay)

$$
\begin{aligned}
& 30.0 \% \\
& 30.0 \%
\end{aligned}
$$

$30.0 \%$

$15.0 \%$

$5.00 \%$

$5.00 \%$

$3.00 \%$

$1.74 \%$

$1.00 \%$

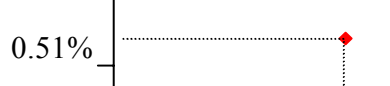

$0.00 \%$

$0.00 \%$

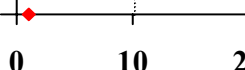

10

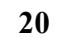

30

40

50

60

70

80

90

100

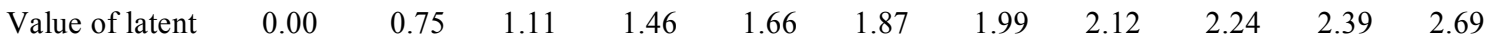
dependent variable 